Revista InterteXto / ISSN: 1981-0601

v. 10, n. 1 (2017)

\title{
OS PROCEDIMENTOS RETÓRICOS DO PRÓLOGO DA HISTORIA DE LA CONQUISTA DE MÉXICO
}

\author{
THE RHETORICAL PROCEDURES IN THE PROLOGUE OF \\ HISTORIA DE LA CONQUISTA DE MÉXICO
}

\section{Deolinda de Jesus Freire(UFTM) ${ }^{1}$}

\begin{abstract}
RESUMO: A partir de preceitos das artes retóricas de Aristóteles, Quintiliano e Cícero, bem como de manuais castelhanos do século XVI, sobre os proêmios, nosso objetivo é discutir os procedimentos retóricos aplicados por Dom Antonio de Solís no prólogo da Historia de la conquista de México, publicada pela primeira vez em 1684. O prólogo, ao lado das aprovações oficiais e da censura, integra a parte introdutória da edição impressa e se caracteriza como o lugar em que o autor enuncia a si próprio como leitor de sua obra, inventando, a partir de lugarescomuns, a imagem de si mesmo. A função primordial de Solís no prólogo - "A los que leyeren" - é tornar o leitor dócil, atento e benevolente, e fazer com que ele, lendo a obra, não a censure. É nesse texto que Solís manifesta suas qualidades e as do livro, sempre com afetada modéstia, e se esforça para regular uma interpretação que ele não pode dominar completamente, aliás, como também todos os discretos que ajuízam a obra nos discursos oficiais e preliminares da obra.
\end{abstract}

Palavras-chave: Artes retóricas; Prólogo; México; Solís.

ABSTRACT: Starting from Aristotle, Quintilian and Cicero's precepts of rhetorical arts, as well as from $16^{\text {th }}$ century manuals of Castilian, our goal is to discuss the rhetorical procedures used by Dom Antonio de Solís in the prologue of Historia de la conquista de México published for the first time in 1684. The prologue, along with the official endorsement and censorship, is part of the printed edition's introduction and it's characterized as the place where the author enunciates himself as a reader of his work, creating, from commonplaces, the image of oneself. Solís' prime function in the prologue - "A los que leyeren" - is to make the reader docile, attentive and benevolent, and for him not to censor the book while reading it. It's in this text that Solís manifests his qualities and those of the book, always affected with modesty, and strives to regulate an interpretation which he cannot completely master - by the way, as well as all the discrete ones that judge the Historia in the official and preliminary discourses of the literary work.

Keywords: Rhetorical Arts; Prologue; México; Solís.

${ }^{1}$ Profa. do Departamento de Estudos Literários do curso de Letras da UFTM 


\title{
Revista InterteXto / ISSN: 1981-0601
}

\author{
v. 10, n. 1 (2017)
}

\section{Introdução}

A primeira edição da Historia de la conquista de México de Dom Antonio de Solís, publicada em Madri no ano de 1684, teve como base para o estabelecimento final do texto dois manuscritos: o borrador autógrafo e uma cópia amanuense com emendas autógrafas. $^{2}$ O primeiro manuscrito, catalogado pela Colección Salazar, é um rascunho revisado e corrigido pelo próprio cronista, como atesta Luis A. Arocena (1963) em sua obra Antonio de Solís, cronista indiano. Já o segundo manuscrito, conservado pela Biblioteca Nacional de Madri, contém múltiplas e diversas correções autógrafas do próprio Solís, razão pela qual deve ser considerado o texto final da edição princeps (GRIGERA, 1985). Ademais, foi o exemplar apresentado ao conselho real para que fossem emitidas as aprovações, as licenças, a censura e o privilégio do rei. Como comprovam, segundo Grigera (1985, p. 489), as folhas rubricadas por Aresti na licença de impressão em que há a indicação de que se imprima "por el original que en nuestro Consejo se vio, que va rubricado y firmado por Gabriel de Aresti y Larrazábal".

A edição princeps da Historia de la conquista de México é dividida em, pelos menos, três partes: a introdutória, o miolo, que é composto por cinco livros, e o índice das coisas notáveis, que encerra a obra. A parte introdutória é constituída pelas dedicatórias de Solís ao rei Carlos II e ao Conde de Oropesa - filho do protetor de Solís e também quem entregou pessoalmente o volume ao rei -, pela censura de Dom Gaspar de Mendoza e pelas aprovações de Padre Jacinto, Dom Luis de Cerdeño e Dom Nicolas Antonio, além do prólogo aos leitores, que é o objeto de nossa leitura e análise neste artigo. Esses discursos da parte introdutória são, claramente, divididos em duas categorias: autorais, escritos pelo próprio Solís, e oficiais, escritos pelos primeiros leitores discretos ${ }^{3}$ que tiveram de ajuizar e aprovar a obra para a publicação.

\footnotetext{
${ }^{2}$ Sobre os dois manuscritos da Historia de la conquista de México de Solís, ver o ensaio "Para la edición crítica de la Historia de la conquista de México de Antonio de Solís" de Luisa López Grigera (1985).

${ }^{3}$ Segundo Hansen, "o destinatário discreto é figurado como capacidade de ajuizar a aptidão técnica da forma poética, valorizando o artifício aplicado. Ou seja, o discreto é o tipo caracterizado pelo engenho retórico e pela prudência política típicos da racionalidade de Corte divulgada institucionalmente, no Estado do Brasil, no ensino organizado a partir de 1599 pelos modelos do Ratio studiorum da Companhia de Jesus. Segundo Inácio de Loyola, a discretio não é diferente da caritas, pois é a capacidade de fazer juízos justos e prudentes. O tipo discreto é erudito e domina as artes da memória que Ihe permitem conhecer todos os lugares-comuns aplicados aos poemas. Por isso, testemunha a força do sistema de regras, que conhece e reconhece, como um equivalente direto ou um sinônimo da auctoritas figurada nos poemas. [...] Por oposição, o destinatário vulgar só recebe os efeitos pois, figurado como ignorante do preceito técnico
} 


\title{
Revista InterteXto / ISSN: 1981-0601
}

\author{
v. 10, n. 1 (2017)
}

Como deixa entrever o próprio título da obra, Dom Antonio de Solís não toma da pena para escrever a respeito de um acontecimento novo para o século XVII, afinal a queda de Tenochtitlán e a conquista dos aliados astecas ocorrem na primeira metade do $\mathrm{XVI}$, entre 1519 e 1522. Ademais, essa conquista foi narrada por outros cronistas, além do próprio conquistador, Hernán Cortés, e um de seus soldados, Bernal Díaz del Castillo. O motivo que leva Solís a eleger essa conquista para sua história, entre tantas empreendidas nas Índias Ocidentais, é o fato de acreditar que a conquista do México é um dos maiores argumentos que celebra o mundo em seus Anais. Solís ainda justifica que a conquista da Nova Espanha ${ }^{4}$ ainda não possui uma História digna de seus grandes feitos, pois ainda Ihe falta o estilo elevado do gênero histórico, como o que foi empenhado pelo Inca Garcilaso de la Vega em Comentarios Reales que narra a história da conquista do Peru, cuja narração é ajuizada por Solís como "tan puntual en las noticias, y tan suave, y ameno en el estilo", logo, de difícil emulação. Assim, a história (re)escrita por Solís não narra fatos novos para os leitores (discretos), que sabem o que vão encontrar na narração, a novidade estaria no modo de narrar (estilo).

Para os cronistas de uma monarquia ibérica do XVII, como Dom Antonio de Solís, narrar é convencer de uma versão dos fatos de acordo com o que convém ao propósito da narração, cujas descrições têm como função julgar moralmente tantos os homens que participaram das ações como os que foram subjugados. Assim, a escrita do cronista destaca-se como um dos principais recursos artificiais para vencer o tempo e o esquecimento, trazendo à tona a ideia ciceroniana da História, que é "testemunha dos tempos, mestra da vida e luz da verdade". 5 No XVII, o compromisso com a verdade supunha uma chave de leitura sacramental dos acontecimentos e conferia ao império um

que os produz, é constituído negativamente pelo manuscrito como incapaz de lê-lo, ou seja, de fazer as distinções dos agrupamentos da sua dispositio. Isso não significa que, segundo as prescrições do século XVII, os vulgares sejam insensíveis à poesia coletada. Podem ser afetados por ela e reagir a seus efeitos, mas não conhecem ou não compreendem o artifício ou as regras que presidiram sua invenção." HANSEN, João Adolfo. "Barroco, neobarroco e outras ruínas”. In: Floema. Caderno de Teoria e História Literária. Especial “João Adolfo Hansen”. Ano II, n. 2. Vitória da conquista: Edições UESB, outubro 2006, p. 44.

${ }^{4}$ É útil lembrar que, para os séculos XVI e XVII, Nova Espanha designava toda a região que hoje compreende o país México. Já México designava a capital do povo asteca: Tenochtitlán.

${ }^{5}$ Esse conceito ciceroniano de história é apresentado pela voz de Marco Antônio em De Oratore: "A história, na verdade, testemunha dos tempos, luz da verdade, vida da memória, mestra da vida, mensageira da Antigüidade, com que palavra, a não ser a do orador, será confiada à eternidade?". Apud FLORENZANO, Modesto. "Prefácio". In: 


\title{
Revista InterteXto / ISSN: 1981-0601
}

\author{
v. 10, n. 1 (2017)
}

sentido providencial. Para desvelar a verdade, que é a alma da História, os historiadores deviam se valer de testemunhos escritos e oculares, uma vez que as marcas divinas estariam assinaladas no mundo e nos episódios relatados. ${ }^{6}$ A estrutura da narração das Historias das Índias é teleológia e sempre providencial, pois Deus é a causa primeira e também a última. Todos, principalmente os príncipes, devem "amá-lo acima de todas as coisas e voltar para ele todas as suas ações como verdadeiro fim" .

Como gênero, a história aproxima-se do epidítico, ou demonstrativo, da oratória porque, como este, tem como preceitos o encômio e o louvor (ou vituperação) dos grandes homens e suas ações. Os procedimentos retóricos aplicados para retratar o caráter dos grandes homens assemelham-se aos aplicados na épica para inventar o herói. Porém, oposta à ordem artificial da épica, a narração histórica tem uma disposição prescrita como ordem natural, que narra do mais recuado do passado em direção ao presente do historiador, sendo que este presente configura a enunciação da narração. Tais conceitos sobre a arte histórica e os procedimentos retóricos aplicados pelo cronista em sua narração podem ser lidos e confirmados na parte introdutória da Historia de la conquista de México de Solís, principalmente nos discursos dos primeiros leitores discretos que ajuizaram a obra tanto pelo seu valor estético como moral. Já o prólogo, marcado pela voz do próprio autor, encerra o juízo moral e estético da História.

\section{Os paratextos e as imagens de autor e leitor}

O manuscrito e sua materialidade carregam consigo uma memória. A materialidade transforma a escrita em objeto de leitura, ou seja, o manuscrito torna-se livro, que é manuseado e lido por aquele que tiver acesso a ele. Obviamente, o manuscrito também é objeto de leitura, no entanto sua materialidade não é a mesma de uma edição impressa, logo, seu círculo de leitura é mais restrito. O livro possibilita a

\footnotetext{
AMBROSIO, Renato. De rationibus exordiendi: os princípios da história em Roma. São Paulo: Humanitas / Fapesp, 2005. p. 16.

${ }^{6}$ Essa ideia está baseada na leitura do ensaio "Os preceitos da memória: Manuel Severim de Faria, inventor de autoridades lusas" de Luiz Cristiano de Andrade (2006, p. 134).

${ }^{7}$ Essa frase do Sr. Otaviano, personagem que participa das discussões sobre o cortesão, refere-se aos cuidados que deve ter um príncipe em seu governo. CASTIGLIONE, Baldassare. O cortesão. Tradução de Carlos Nilson Moulin Louzada. Revisão de Eduardo Brandão. São Paulo: Martins Fontes, 1997, p. 297. O argumento da obra é o de relatar os encontros de quatro noites, de três a sete de março de 1506, nos aposentos do palácio do Duque de Urbino, Guidubaldo di Montefeltro (1472-1508), a quem serviu Castiglione como militar, diplomata e letrado. Os diálogos entre os nobres presentes buscam o modelo do perfeito cortesão.
} 


\title{
Revista InterteXto / ISSN: 1981-0601
}

\author{
v. 10, n. 1 (2017)
}

ampliação do número de leitores, sendo que alguns deles podem também ser os leitores de manuscritos, mas esse privilégio não se estende a todos. Afinal, nos séculos XVI e XVII, ler era um privilégio da elite, ou seja, de uma pequena parte da população.

A materialidade permite perceber os elementos que transformam o manuscrito em livro. Entre eles, há aqueles que são puramente ornamentais, cuja função é tornar a disposição do texto e sua organização mais prazerosa, como exemplo temos as vinhetas, as capitulares e os traços. Ao lado desses, há outros elementos que, no conjunto, engendram um lugar que é marcado pelo encontro entre o texto e o leitor, que, por sua vez, está permeado pela leitura dos primeiros leitores, ou seja, os discretos. Os discursos que compõem a parte introdutória, ou seja, o frontispício, as dedicatórias, censuras e aprovações, juntamente com os elementos puramente ornamentais, são tratados pela crítica como paratextos, termo cunhado em 1982 por Gérard Genette em Palimpsestes. ${ }^{8}$

Para Cayuela (1996, p. 133), o paratexto, além de ser o lugar do primeiro encontro entre o texto e o leitor, é também onde se cria uma imagem que o acompanhará ao longo do livro: a imagem de um autor que, desde o frontispício, se oferece através da marca de seu estado civil, que se desdobra nas apresentações escritas por outros e, finalmente, se apresenta e representa a si mesmo nos textos preliminares autorais. Sobre o autor, entendemos que ele nasce no ato da leitura, pois, levando em consideração Foucault (2006, p. 274), o autor não é um conceito mas uma função, e esta é característica do modo de existência, de circulação e de funcionamento de certos discursos no interior de uma sociedade. Como nos lembra Borges, "una de las obras más importantes de un escritor - quizá la más importante de todas - es la imagen que deja de sí mismo a la memoria de los hombres, más allá de las páginas escritas por él"9. Os paratextos, ou seja, a parte introdutória do livro - o frontispício, as censuras do Estado e

\footnotetext{
${ }^{8} \mathrm{O}$ paratexto é um dos cinco tipos de relações 'transtextuelles' apresentadas por Genette (1982, p. 9): « Le second type est constitué par la relation, généralement moins explicite et plus distante, que, dans l'ensemble formé par une œuvre littéraire, le texte proprement dit entrétient avec ce que l'on ne peut guère nommer que son paratexte : titre, sous-titre, intertitres; préfaces, postfaces, avertissements, avant-propos, etc. ; notes marginales, infrapaginales, terminales ; épigraphes ; illustrations ; prière d'insérer, bande, jaquette, et bien d'autres types de signaux acessoires, autographes ou allographes, qui procurent au text un entourage (variable) et parfois un commentaire, officiel ou officieux, dont le lecteur le plus purist et le moins porté à l'erudition externe ne peut pas toujours disposer aussi facilement qu'il le voudrait et le prétend. ". Grifo nosso.

9 Borges desenvolve esse conceito como base para a afirmação de que, pessoalmente, Wordsworth foi um poeta superior a Samuel Taylor Coleridge, de quem trata na aula de 16 de novembro de 1966. ARIAS, Martín; HADIS, Martín. Borges Profesor. Curso de literatura inglesa en la Universidad de Buenos Aires. Edición, investigación y notas de Martín Arias y Martín Hadis. Buenos Aires: Emecê Editores, 2001, p. 179.
} 


\title{
Revista InterteXto / ISSN: 1981-0601
}

\author{
v. 10, n. 1 (2017)
}

da Igreja (aprovações e licenças), as preliminares autorais (dedicatórias e prólogos) contribuem para a construção dessa memória e imagem do autor, bem como da significação da obra que precedem.

O prólogo ao leitor e as dedicatórias são lugares em que o cronista enuncia a si próprio como leitor de sua obra, inventando, a partir de lugares-comuns, a imagem de si mesmo. Os discursos oficiais, que acompanham os autorais, reverberam essa imagem. É a imagem inventada na parte introdutória, tanto por Solís como pelos primeiros leitores de sua obra, que the permite um futuro de glória e fama ${ }^{10}$ como cronista, e que estas se estendam à conquista que narra, ao herói que a concretiza e à sua nação. ${ }^{11}$ Decorosamente, a glória e a fama são atribuídas, servil e humildemente, às figuras do rei Carlos II e do Conde de Oropesa nas dedicatórias, pois Solís, por pudor 'regrado', não ousa reivindicá-las em seu nome. Assim, temos a imagem de um homem discreto, que segue o decoro cristão, e dedicado às letras, lembrando aqui que a correspondência entre a função social e o exercício da pena é um parâmetro particularmente de prestígio para os escritores dos séculos XVI e XVII.

\section{Autor e leitor: "A los que leyeren"}

O prólogo de Dom Antonio de Solís, intitulado "A los que leyeren", é o discurso que instaura o contato do autor com o leitor. Sua inserção na obra impressa impõe um duplo papel, pois, por ser o último da parte introdutória, o prólogo encerra as dedicatórias e os discursos oficiais e, ao mesmo tempo, abre a Historia de la conquista de México. A função primordial do autor, ao escrever o prólogo, bem como o proêmio, é tornar o leitor dócil, atento e benevolente, e fazer com que ele, lendo a obra, não a censure. No entanto, o autor não busca uma leitura aleatória, mas sim uma leitura regrada a partir dos preceitos do gênero e do decoro cristão. Como nos lembra Arnaud Tripet (1992, p. 4), "le

\footnotetext{
${ }^{10}$ Fama quer dizer eternidade humana, aperfeiçoada natureza, superação da mortalidade, alvo enfim de toda poesia e pintura perfeitas, ou seja, de toda arte. Apud MUHANA, Adma. "Introdução". In: Poesia e pintura ou pintura e poesia: tratado seiscentista de Manuel Pires de Almeida. São Paulo: Editora da USP/ FAPESP, 2002, p. 46.

${ }^{11}$ Esse termo é mencionado, frequentemente, nos discursos da parte introdutória. No prólogo ao leitor, por exemplo, Solís afirma sobre os historiadores estrangeiros: "no pueden sufrir la Gloria de nuestra Nacion, ni acaban de conocer lo que obran contra si en estas Cabilaciones: pues descubren la flaqueza de su Emulacion, y ordinariamente queda mejor el Imbidiado". Solís refere-se, obviamente, à nação espanhola; em outros momentos, usará o termo para se reportar ao México. Atualmente, tanto o México como a Espanha, bem como outras regiões da Europa do século XVI e XVII, não são considerados como uma nação, pois tal termo está carregado de implicações teóricas advindas, principalmente, da ideologia do XIX. Dessa forma, esclarecemos que usamos o termo com o mesmo sentido em que é mencionado nos discursos da parte introdutória, ou seja, para se referir a um determinado povo.
} 


\title{
Revista InterteXto / ISSN: 1981-0601
}

\author{
v. 10, n. 1 (2017)
}

texte liminaire s'emploie à définir un comportement de lecteur, l'image d'un bon lecteur". O prólogo é o lugar de escritura em que o autor manifesta suas qualidades e as da obra, sempre com afetada modéstia, e se esforça para regular uma interpretação que ele não pode dominar completamente, aliás, como também todos os homens discretos e, obviamente, nobres, que ajuizaram e aprovaram a Historia de la conquista de México.

O discurso prologal põe em evidência tanto a voz do cronista, que se apresenta em primeira pessoa, quanto o lugar de sua enunciação, que não é a mesma da escrita da obra nem das dedicatórias e aprovações. Estas últimas, por exemplo, marcam o início de um processo para conseguir a permissão para publicar o livro. Já no prólogo, temos o presente imediato da publicação, ou seja, quando a obra é, finalmente, 'dada à luz'. No prólogo de Solís, esse presente é marcado, principalmente, pelo uso do advérbio "oy" em dois momentos. No segundo parágrafo, Solís, ao expor sobre o argumento de sua Historia e a grandeza do assunto, afirma com afetada modéstia: "y me desalienta oy, poniendome à la vista los peligros de mi Pluma". No último parágrafo, após dissertar sobre o estilo, afirma: "En el estilo, pues, que me señalò esta Gran Maestra [a natureza], escrivì la Historia que sale oy á luz" ${ }^{12}$ Essas afirmações, além da enunciação, também ressaltam que, no prólogo, o autor estabelece um diálogo não apenas com o leitor, mas também com sua própria obra.

Em ambos os diálogos, Solís busca estabelecer a confiança com o leitor, com sua obra e consigo mesmo. De acordo com o Anônimo da Retórica a Herênio (2005, p. 59), essa tripla utilidade deve ser buscada ao longo de todo o discurso, embora seja preparada, sobretudo, no exórdio, ou seja, no prólogo:

7. [...] Poderemos fazer dóceis os ouvintes se expusermos brevemente a súmula da causa e se os tornarmos atentos, pois é dócil aquele que deseja ouvir atentamente. Teremos ouvintes atentos se prometermos falar de matéria importante, nova e extraordinária ou que diz respeito à República, ou aos próprios ouvintes, ou ao culto dos deuses imortais; se pedirmos que ouçam atentamente e se enumerarmos o que vamos dizer. 8. Podemos tornar os ouvintes benevolentes de quatro maneiras: baseados em nossa pessoa, na de nossos adversários, na dos ouvintes e na própria matéria.

\footnotetext{
12 Todos os grifos das citações são de nossa autoria. O arcaísmo das citações da Historia de Solís foi mantido, pois utilizamos em nosso trabalho a edição princeps de 1684.
} 


\title{
Revista InterteXto / ISSN: 1981-0601
}

\author{
v. 10, n. 1 (2017)
}

Para tornar o leitor dócil, logo nas primeiras linhas, Solís afirma que não tratará da introdução da obra, ou proêmio, como estilaram os antigos, porque decidiu colocá-la nos primeiros capítulos da Historia, momento em que exporá os motivos que o 'obrigaram' a escrevê-la. Dessa forma, logo de entrada, o leitor sabe que o prólogo de Solís será breve, pois o cronista não se estende em explicar os juízos sobre os historiadores espanhóis e estrangeiros que trataram do mesmo tema que sua História. Para tornar o leitor atento, Solís ajuíza a conquista da Nova Espanha como um dos maiores argumentos que celebra o mundo em seus Anais, prometendo a narração de sucessos admiráveis e heroicos. $\mathrm{Na}$ Retórica, Aristóteles $(2005,1415 b$, p. 282) afirma que o auditório é mais atento a temas importantes, a coisas que the digam respeito, às que os encham de espanto, às agradáveis. E, por último, para tornar o leitor benevolente, Solís louva seu ofício e a si mesmo sem arrogância, sempre com afetada modéstia, pois afirma que deixa ao leitor a liberdade da censura por já estar em uma idade avançada em que deve temer os aplausos como inimigos dos desenganos.

Sobre a escrita da Historia, Solís repete, com modéstia, a afirmação de que cumpre, como pode, com a profissão de cronista que pôs a pluma em sua mão. No final do prólogo, afirma:

[...] y quedaria satisfecho con no desagradar à todos, tan lexos estoy de hazer por mi fama, lo que obré por mi obligacion. Recibanse benignamente, como necessarios à la Introduccion de la Historia, estos Presupuestos de mi ingenuidad: y sobre todo imploro la benevolencia de los que leyeren este Libro, para que me sean testigos, de que no ay en él palabra, ò sentencia, que no vaya sujeta enteramente à la Correccion de la Santa Iglesia Catholica Romana, à cuyo infalible dictamen rindo mi entendimiento, confessando que pudo errar la ignorancia, sin noticia de la voluntad. (SOLís, 1684, s/pág.)

A humildade é empregada no prólogo de forma decorosamente cristã, pois Solís qualifica seus pressupostos como ingênuos, ou seja, simples e singelos; implora a benevolência do leitor e confessa que se errou foi sem intenção de sua vontade, mas sim pela influência da ignorância. Ademais, torna os leitores testemunhas, quiçá cúmplices, de que sua obra está totalmente sujeita à correção da Santa Igreja Católica Romana. Em seu prólogo, Solís segue os preceitos do gênero oratório epidítico, ou demonstrativo, pois elogia, modestamente, sua pessoa, a matéria que trata e seus 


\title{
Revista InterteXto / ISSN: 1981-0601
}

\author{
v. 10, n. 1 (2017)
}

leitores; em contrapartida, vitupera os historiadores que não obraram com a verdade sobre as notícias da conquista da Nova Espanha, principalmente os estrangeiros, que se tornam os principais adversários em seu discurso. Sobre eles, o cronista afirma que "no pueden sufrir la Gloria de nuestra Nacion, ni acaban de conocer lo que obran contra si en estas Cabilaciones: pues descubren la flaqueza de su Emulacion, y ordinariamente queda mejor el Imbidiado". Com esse juízo, Solís move os leitores a sentimentos de indignação e desprezo, pois acusa os historiadores estrangeiros e suas nações do pecado da inveja. Por não suportarem a glória alcançada pela Espanha com a conquista do México, as nações estrangeiras tentam macular as memoráveis ações de Hernán Cortés, que, apesar do tempo, ainda fazem brilhar o império de Carlos V, um passado glorioso e modelar para todos os monarcas. Essas nações, ainda que tentem imitar as ações espanholas, são fracas na emulação, o que torna aquele que é invejado ainda mais grandioso. Com esse discurso, Solís conquista a benevolência do leitor porque elogia, modestamente, sua pessoa, a matéria de que trata e os leitores ao mesmo tempo em que vitupera seus adversários na escrita, bem como os da Espanha, ou seja, os historiadores estrangeiros.

No diálogo com sua obra, o cronista concentra-se em dois pontos cruciais para o gênero historiográfico nos séculos XVI e XVII: os adornos da eloquência em relação à pontual verdade e o estilo adequado. Sobre os adornos, Solís reflete:

Los Adornos de la Eloquencia son accidentes en la Historia, cuya substancia es la Verdad, que, dicha como fue, se dize bien: siendo la puntualidad de la noticia, la mejor elegancia de la Narracion. Con este conocimiento he puesto en la certidumbre de lo que refiero, mi principal cuydado. Examen, que algunas vezes me bolvió à la tarea de los Libros, y Papeles: porque hallando, en los Sucessos, ò en sus circunstancias, discordantes, con notable oposicion, á nuestos mismos Escritores, me ha sido necessario buscar la Verdad con poca luz, ò congeturarla de lo mas verisimil; pero digo entonces mi reparo: y si llego à formar opinion, conozco la flaqueza de mi dictamen, y dexo lo que afirmo al arbitrio de la razon. (SOLís, 1684, s/pág.)

Com afetada modéstia, pois afirma conhecer a fraqueza de seu juízo, Solís enaltece o seu trabalho ao demonstrar o quão difícil foi chegar à verdade dos sucessos, pois muitos deles foram narrados de forma discordante, com notável oposição, até mesmo pelos historiadores espanhóis. Em razão dos obstáculos, Solís procurou a 


\title{
Revista InterteXto / ISSN: 1981-0601
}

\author{
v. 10, n. 1 (2017)
}

verdade com pouca luz, por isso, muitas vezes, teve de conjeturá-la a partir do mais verossímil. O historiador, como nos adverte Luciano de Samósata (2009, p. 97), deve ter como objetivos a franqueza e a verdade, logo, sua linguagem deve mostrar claramente os fatos e fazê-los aparecer em plena luz. Samósata $(2009$, p. 75$)$ afirma que não se deve juntar os fatos ao acaso, pois é preciso, ao preço de mil penas e sofrimentos, comprová-los; ensinamento que Solís demonstra observar e seguir em suas ponderações. Para exercer bem seu ofício, o historiador deve confiar em quem expõe os fatos com mais integridade, por isso deve ser hábil para visar e dispor o que é mais convincente ou o que mais se aproxima do verossímil. Por essas razões, Solís ajuíza que os adornos da eloquência são como acidentes, ou seja, acessórios, para o gênero da História, cuja substância é a verdade, logo, a melhor elegância para sua narração é a "puntualidad de las noticias". Solís segue os preceitos do gênero que determinam que o útil deve se sobrepor ao prazeroso, sendo que a utilidade só pode ser alcançada a partir do verdadeiro. Como sentencia Samósata (2009, p. 41), a História, se além do útil se ocupa com o prazeroso, pode atrair muitos amantes, mas, até que tenha atingido sua finalidade própria - a publicação da verdade - se preocupará pouco com a beleza, ou seja, com os adornos da eloquência que Solís afirma serem acidentais.

Sobre o estilo, Solís adverte que seu acerto se deve à adequada eleição das vozes, à colocação das palavras e à formação dos períodos. Por isso, governou-se pelo que observaram os autores de maior qualificação, ajustando seu estilo aos termos mais rigorosos da língua castelhana, que, em seu 'sentir', é capaz de toda propriedade que corresponde à essência das coisas, e de todo ornato que, alguma vez, é necessário para adoçar o útil da oração. Sobre os gêneros que governam o estilo, defende:

A tres generos de darse à entender con las palabras, reducen los Eduditos el Caracter, ò el Estilo de que se puede usar en diferentes Facultades, y todos caben, ò son permitidos en la Historia. El Humilde, ò familiar (que se usa en las cartas, ò en la conversacion) pertenece à la Narracion de los Sucessos. El Moderado (que se prescribe à los Oradores) se debe seguir en los Razoamientos, que algunas vezes se introducen, para dar à entender el fundamento de las Resoluciones. Y el Sublime, ó mas Elevado (que solo es peculiar à los Poetas) se puede introduzir con la debida moderacion, en las Descripciones, que son como unas Pinturas, ò Dibujos de las Provincias, ó Lugares donde sucediò lo que se refiere, y necessitan de algunos colores para la informacion de los ojos. (SOLís, 1684, s/pág.) 


\title{
Revista InterteXto / ISSN: 1981-0601
}

\author{
v. 10 , n. 1 (2017)
}

O estilo da Historia de la conquista de México abarca os três gêneros: o humilde, o moderado e o sublime, logo, o baixo, o médio e o alto. Cada um deles, respectivamente, foi empenhado nas três partes que compõem sua Historia: narração dos sucessos, razoamentos das resoluções e descrição das províncias ou lugares. Os três estilos mencionados são os que regem a oratória na antiguidade, bem como as artes em geral. Quintiliano trata dessas três partes no último livro da Instituição Oratória após argumentar sobre as diferenças de estilo entre áticos e asiáticos. A divisão tripartida é própria para distinguir os diferentes gêneros oratórios - deliberativo, judiciário e epidítico - bem como os gêneros da eloquência. Assim, o primeiro estilo é considerado simples, o segundo é alto e forte, e o terceiro é chamado por alguns de intermediário e por outros de florido.

Adma Muhana (2002, p. 23) aborda esses três estilos, a partir da leitura do discurso de arte poética de Tasso, na aplicação ao gênero poético. Muhana afirma que há uma identificação da tragédia e da épica com o sublime, que comporta pureza e simplicidade de palavras, planura e elegância, com poucas mas elevadas figuras, propícias ao movere (persuadir); a comédia é identificada com o estilo baixo, que produz um discurso claro, com o uso de termos vulgares e também poucos ornatos ou figuras de linguagem, destinado ao docere (ensinar); e a lírica - por outra, aquele em que o modo do discurso é em primeira pessoa, ou "narrativo" -, é identificada com o estilo medíocre ou mediano, "igual", ao mesmo tempo plácido nas coisas tratadas e figurado nos termos que as enformam, adequado ao delectare (deleitar). Solís empenha os três estilos, que são identificados tanto na arte oratória como na poética, buscando docere, delectare e movere a todos os leitores. Como afirma Dom Gaspar na Censura da edição princeps, a Historia de la conquista de México merece o aplauso dos homens discretos e doutos, além de ser compreensível para os rudes e vulgares. Lembramos ainda que o estilo deve ser regrado de acordo com o decoro do gênero, sendo que a História deve valorizar o médio sem descuidar-se, obviamente, do alto, ou sublime, que, segundo Solís, é aplicado nas descrições de pessoas e lugares.

Apesar de mesclar os três estilos em sua Historia, Solís, modestamente, afirma que não soube entender-se com suas diferenças porque muito se caminha entre 


\title{
Revista InterteXto / ISSN: 1981-0601
}

\author{
v. 10, n. 1 (2017)
}

especulação e prática, no entanto, pondera que se esforçou para seguir os melhores vestígios. Confessa, ainda, que teve intento de imitar Tito Lívio, inclinação que logo se mostrou como uma insolúvel dificuldade; assim, o cronista crê que não pode haver perfeita imitação no estilo dos homens porque cada um fala e escreve com alguma diferença em virtude de seus dialetos. A imitação de Tito Livio só não pôde ser perfeita em virtude da pureza da língua castelhana que empenha em seu estilo, como determina o sublime do gênero. Com esse discurso, Solís conquista a docilidade, a atenção e a benevolência do leitor, principalmente aquele que aprecia o idioma castelhano, porque o leva a compartilhar do elogio e da defesa desse 'dialeto'.

\section{Considerações finais}

A função primordial de Dom Antonio de Solís no prólogo - "A los que leyeren" da Historia de la conquista de México é tornar o leitor dócil, atento e benevolente, e fazer com que ele, lendo a obra, não a censure. No entanto, o autor não busca uma leitura aleatória, mas sim uma leitura regrada a partir dos preceitos do gênero e do decoro cristão. O prólogo e os discursos oficiais da parte introdutória da Historia de Solís, ou seja, os paratextos, contribuem para que o leitor atual conheça o mundo regrado dos séculos $\mathrm{XVI}$ e XVII e entre em contato com os preceitos que regeram os gêneros historiográficos da época colonial, bem como seus subgêneros. Atualmente, boa parte das edições 'modernizadas' das obras coloniais não trazem os textos introdutórios que auxiliariam o leitor a compreender sobre o momento de escrita e publicação da obra.

É útil assinalar que no contexto histórico em que se produziram os discursos sobre a conquista das Índias Ocidentais, esses eram regidos pelos ideais católicos. A partir do século XVI, a Contrarreforma propõe a história sacra como modelo de uma vida beata ou católica oposta a uma vida libertina ou protestante ou maquiavélica, sendo que as artes em geral foram definidas pelos jesuítas como theatrum sacrum, ou seja, teatro sacro, e figuração da história sacra. Essa figuração também participa do discurso histórico, sendo uma de suas formas a presença constante da providência divina na narração das ações singulares e da vida dos grandes homens que são retratados pela História. Como adverte Mendiola (2003, p. 46), a História, para o escritor do século XVI, é 


\title{
Revista InterteXto / ISSN: 1981-0601
}

\author{
v. 10, n. 1 (2017)
}

observada desde o esquema bíblico da instituição eclesiástica. Como exemplo, o historiador menciona a queda de Tenochtitlán:

[...] el relato de la caída de Tenochtitlan se construye (morfológicamente) imitando otras historias que se enmarcan en el mismo esquema (en este caso la caída de un gran imperio). El tiempo para el cronista consiste en la diferencia entre lo eterno y lo corruptible. Lo eterno evidentemente es lo que Dios ve, y Él ve desde la eternidad a diferencia de los seres humanos, que la hacen desde lo terrenal, que es efímero. Todo lo que sea eterno es mejor que lo corruptible, por eso es mejor el alma que el cuerpo, las ideas que lo real, etcétera. Por lo tanto, la caída de Tenochtitlan, desde lo eterno de la mirada de Dios, siempre está cayendo, es decir, la sociedad del siglo XVI no puede pensar lo contingente. [...] (2003, p. 247)

Os leitores, principalmente os discretos, dos séculos XVI e XVII compartilham dos mesmos preceitos retóricos, eclesiásticos e morais do cronista. Assim, o leitor sabe o que vai encontrar nos discursos coloniais no que se refere ao tema e ao modo como este é narrado. E o cronista não pretende, nem deve, frustrar as expectativas de seus leitores. Para ele, narrar é convencer de uma versão dos fatos de acordo com o que convém ao propósito da narração, cujas descrições têm como função julgar moralmente tantos os homens que participaram das ações como os que foram subjugados, ademais de observar a presença da providência divina nas ações dos heróis.

O prólogo pode ser lido a partir da intersecção de duas exigências contraditórias que estão ligadas à sua própria natureza. A primeira é a de que deve ser um discurso funcionalmente definido e previsível porque é limitado em seus componentes, principalmente pela exigência de ser breve. A segunda é a de que deve ser estimulante para suscitar o interesse por si próprio e pela obra a partir dos ideais católicos e morais da época em que se publica a obra. O prólogo de Solís não está isolado no que se refere a essas exigências, pois elas se estendem aos discursos oficiais, que são firmados pelos primeiros leitores discretos da obra. Esses paratextos - prólogo e discursos oficiais -, que antecedem a narração das heroicas conquistas da Nova Espanha, buscam legitimar a obra e persuadir o leitor a compartilhar de uma leitura que ensina e deleita, logo, cumpre com o objetivo primordial do gênero historiográfico que é o de ser útil. O prólogo, bem como os discursos oficiais, representa um espaço de leitura regrada pelo autor. $O$ mundo regrado dos séculos XVI e XVII reflete-se nas edições do livro e nos discursos que o 


\title{
Revista InterteXto / ISSN: 1981-0601
}

\author{
v. 10, n. 1 (2017)
}

legitimam. A obra, que é dada à luz, é um reflexo da organização do mundo políticosocial, histórico e artístico a que pertence.

\section{Referências}

AMBROSIO, Renato. De rationibus exordiendi: os princípios da história em Roma. São Paulo: Humanitas / FAPESP, 2005.

ANDRADE, Luiz Cristiano de. Os preceitos da memória: Manuel Severim de Faria, inventor de autoridades lusas. In: LUZ, Guilherme Amaral. História e Perspectivas, Uberlândia, n. 34, p. 107-137, jan./jun., 2006.

ANÔNIMO. CÍCERO (Atribuição). Retórica a Herênio. Tradução e introdução de Ana Paula Celestino Faria e Adriana Seabra. São Paulo: Hedra, 2005.

ARIAS, Martín; HADIS, Martín. Borges Profesor. Curso de Literatura Inglesa en la Universidad de Buenos Aires. Edición, investigación y notas de Martín Arias y Martín Hadis. Buenos Aires: Emecê Editores, 2001.

ARISTÓTELES. Retórica. Madrid: Editorial Gredos, 1990.

AROCENA, Luis A. Antonio de Solís. Cronista indiano. Buenos Aires: Biblioteca Universitária de Buenos Aires, 1963.

CASTIGLIONE, Baldassare. O cortesão. Tradução de Carlos Nilson Moulin Louzada. Revisão de Eduardo Brandão. São Paulo: Martins Fontes, 1997.

CAYUELA, Anne. Le paratext au siècle d'or. Genève: Librairie Droz, 1996.

FLORENZANO, Modesto. Prefácio. In: AMBROSIO, Renato. De rationibus exordiendi: os princípios da história em Roma. São Paulo: Humanitas/ FAPESP, 2005. p. 13-18.

FOUCAULT, Michel. O que é um autor? In: FOUCAULT, Michel Estética: literatura e pintura, música e cinema. Organização e seleção de textos de Manoel Barros da Motta. Tradução de Inês Autran Dourado Barbosa. Rio de Janeiro: Forense Universitária, 2006. p. 264-298.

GENETTE, Gérard. Palimpsestes. La littérature ou seconde degré. Paris: Editions du Seuil, 1982.

GRIGERA, Luisa López. Para la edición crítica de la Historia de la conquista de México de Antonio de Solís. In: IGLESIAS CANO, María del Carmen; MOYA VALGAÑÓN, Carlos Vicente; RODRÍGUEZ ZUÑIGA, Luis (Orgs.). Homenaje a José Antonio de Maravall. Madrid: Centro de Investigaciones Sociológicas (CIS), 1985. Vol. II. p. 487497.

HANSEN, João Adolfo. Floema. Caderno de Teoria e História Literária. Especial "João Adolfo Hansen". Vitória da Conquista: Edições UESB, outubro 2006.

MENDIOLA, Alfonso. Retórica, Comunicación y realidad. La construcción retórica de las batallas en las crónicas de la conquista. México: Universidad lberoamericana, 2003.

MUHANA, Adma. Poesia e pintura ou pintura e poesia: tratado seiscentista de Manuel Pires de Almeida. São Paulo: Editora da USP/ FAPESP, 2002. 


\title{
Revista InterteXto / ISSN: 1981-0601
}

\author{
v. 10 , n. 1 (2017)
}

QUINTILIEN. Institution Oratoire. Texte revu et traduit avec Introduction et Notes para Henri Bornecque. Vols. I, II, III, IV. Paris: Librairie Garnier Frères, s/d.

SAMÓSATA, Luciano de. Como se deve escrever a história. Tradução e ensaio de Jacyntho Lins Brandão. Belo Horizonte: Tessitura, 2009.

SOLís, Don Antonio de. Historia de la conquista de México. Población y progresos de la América Septentrional conocida por el nombre de Nueva España. Madrid: Imprenta de Bernardo de Villa Diego, 1684.

TRIPET, Arnaud. Montaigne et l'art du prologue au XVIe Siècle. Paris: Librairie Honoré Champion, Editeur, 1992.

Artigo recebido em 08/05/2017

Artigo aceito em 26/09/2017 